\title{
Thermal stability and thermal decomposition of sucralose.
}

\author{
Gilbert Bannach ${ }^{1}$, Rafael R. Almeida ${ }^{2}$, Luis. G. Lacerda³, Egon Schnitzler ${ }^{2}$, Massao Ionashiro $^{4 *}$. \\ ${ }^{1}$ Faculdade de Ciências, UNESP, CEP 17033-360, Bauru, SP, Brazil \\ ${ }^{2}$ Universidade Estadual de Ponta Grossa, UEPG, CEP 84030-900, Ponta Grossa, PR, Brazil. \\ ${ }^{3}$ Universidade Federal do Paraná, UFPR, CEP 80060-000, Curitiba, PR, Brazil \\ ${ }_{4}^{4}$ Instituto de Química, UNESP, C.P. 355, CEP 14801-970, Araraquara, SP, Brazil \\ "massaoi@iq.unesp.br
}

\begin{abstract}
Several papers have been described on the thermal stability of the sweetener, C12H19C13O8 (Sucralose). Nevertheless no study using thermoanalytical techniques was found in the literature. Simultaneous thermogravimetry and differential thermal analysis (TG-DTA), differential scanning calorimetry (DSC) and infrared spectroscopy, have been used to study the thermal stability and thermal decomposition of sweetener.
\end{abstract}

Keywords: Sucralose, thermal behavior, TG, DTA, DSC

\section{Introduction}

Nowadays, human beings are permanently in contact with different compounds biologically active. These are: medicaments, plant growth regulators, active components of food additives as antioxidants, sweeteners and many other compounds.

Escalating prevalence of worldwide obesity and its correlation to other chronic diseases has led to low calorie and sugar free products to move into the main stream of food market. The use of high potency sweeteners has emerged as a major way of reducing calorie intake via complete or partial replacement of calorie laden sucrose in numerous food products [1].

The dietary options that such products provide may be especially helpful in the management of obesity or diabetes mellitus [2]. Consumers also often select such foods and beverages because they want the sweet taste without addition of calories or because they want to reduce the risk of tooth damage.
One group of sweeteners consists of non caloric substances with a very intense sweet taste that are used in small amounts to replace the sweetness of a much larger amount of sugar. The sweeteners of this type that are currently approved for use in worldwide are acesulfame- $\mathrm{K}$, aspartame, neotame, saccharin, alitame, cyclamate, stevia/ steviol glycosides and sucralose [2].

A $2^{\text {nd }}$ group of sweeteners consists of caloric ingredients that can substitute both the physical bulk and sweetness of sugar. Products of this type, sometimes called "sugar replacers" or "bulk sweeteners," include the sugar alcohols (also called "polyols") sorbitol, mannitol, xylitol, isomalt, erythritol, lactitol, maltitol, hydrogenated starch hydrolysates, and hydrogenated glucose syrups [2].

Two new sweeteners, trehalose and tagatose, has similar functions to the polyols although they are actually sugars rather than sugar alcohols. Polyols and other bulk sweeteners are used in food products where the volume and texture of sugar, as well as its sweetness, are important, such 
as sugar-free candies, cookies, and chewing gum. Many of these products are marketed as "diabetic foods" [2].

Sucralose, (1,6-Dichloro-1,6-dideoxy$\beta$-D-fructofuranosyl-4-chloro-4-deoxy- $\alpha-D$ galactopyranoside), is a chlorinated sucrose derivative with enhanced sweetness [3-5].

Sucralose was discovered by British researchers in 1976 [1]. It is obtained from sucrose by a process that replaces three hydroxyl groups by three chlorine atoms the sucrose molecule (Fig. 1).

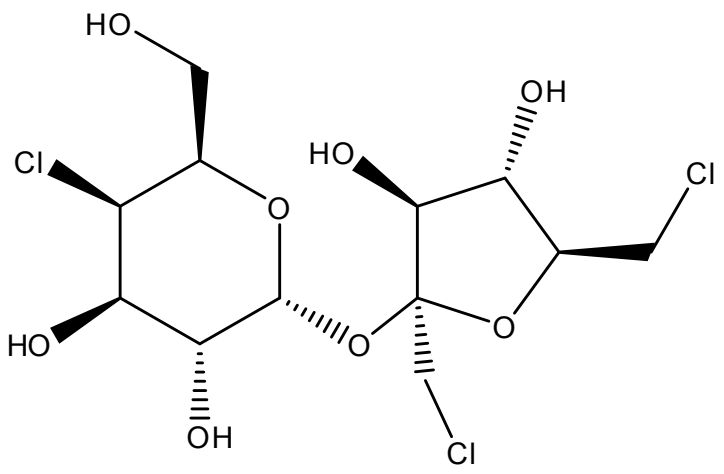

Fig. 1: Structure of sucralose

Although sucralose is made from sugar, the human body does not recognize it as a sugar and does not metabolize it; therefore, it provides sweetness with no calories. Sucralose was approved as a food additive in USA (1988), Canada (1991), UK (2002), European countries (2005), followed by others $[2,6]$. It is potentially 600 times sweeter than sucrose [2].

Sucralose is marketed for home use under the brand name SPLENDA ${ }^{\circledR}$ Low Calorie Sweetener that also includes other concomitants and is available under this name as table top granular and tablet formats. The SPLENDA ${ }^{\circledR}$ brand will also be seen to highlight the use of sucralose as an ingredient in a growing range of low-energy foods and beverages [5].

The use of heat-stable, high-intensity sweetener, such as sucralose, can result in significant improvements in the preparation of reduced-calorie sweet baked goods. In addition, sucralose offers the aqueous and thermal stabilities required for the preparation of consumer-acceptable, reduced-calorie baked goods [7].

The present work deals mainly with the thermal behavior and thermal decomposition of sucralose, since no study using thermoanalytical techniques was found in the literature.

\section{Experimental}

Sucralose with assay $>98.0 \%$ (HPLC - grade), was obtained from Sigma and commercial sucralose (Viafarma, lot $\left.n^{\circ} 1080001\right)$ was acquired in local drugstore (Araraquara - SP - Brazil), and studied by thermoanalytical techniques.

Simultaneous thermogravimetry and differential thermal analysis (TG-DTA) curves were recorded on a model SDT 2960 thermal analysis system from TA Instruments. The purge gas was an air flow of $100 \mathrm{~mL} \mathrm{~min}^{-1}$ and a heating rate of $10^{\circ} \mathrm{C} \mathrm{m^{-1 }}$ was adopted, with samples weighing about $5 \mathrm{mg}$. Alumina crucibles were used for recording the TG-DTA curves.

DSC curves were recorded using a DSC 60 (Shimadzu) under an air flow of $100 \mathrm{~mL} \mathrm{~min}^{-1}$, heating rate of $10^{\circ} \mathrm{C} \mathrm{min}{ }^{-1}$ and aluminum crucibles with perforated cover.

The attenuate total reflectance infrared spectra were recorded on a Nicolet iS10 FT-IR (Thermo Scientific) an ATR accessory with Ge window.

\section{Results and Discussion}

The simultaneous TG-DTA curves of the sucralose from sigma (HPLC - grade) and Viafarma (commercial product) are shown in Fig. 2 and 3, respectively. A close similarity is observed in the TG profiles of these samples, however significative differences are observed in the DTA curves, above $250^{\circ} \mathrm{C}$. These curves also show that the both samples are stable up to $119^{\circ} \mathrm{C}$ and above this temperature the thermal decomposition occurs in three steps up to $550^{\circ} \mathrm{C}$.

The first step that occurs between 119 and $137^{\circ} \mathrm{C}$, corresponding to a sharp endothermic 
peak at $132^{\circ} \mathrm{C}$ in both samples is attributed to the thermal decomposition of the compound with losses of $2 \mathrm{H}_{2} \mathrm{O}$ (water of constitution) together with $1 \mathrm{HCl}($ Calcd $=18.10 \% ; \mathrm{TG}=18.0 \%)$. The last two steps observed between $160-370^{\circ} \mathrm{C}$ and 370 $550^{\circ} \mathrm{C}$, that occur through overlapping ones with total mass loss, corresponding to the exotherm with two peaks at $360^{\circ} \mathrm{C}$ and $500^{\circ} \mathrm{C}$ (Sigma) or a single exothermic peak at $360^{\circ} \mathrm{C}$ (Viafarma), are attributed to the oxidation of the organic matter.

The loss of constitution water and hydrogen chloride in the first step were confirmed through an experiment with samples of sucralose heated in a tube glass up to $140^{\circ} \mathrm{C}$ as indicated by the TGDTA curves.

In this experiment, the condensation of water in the tube glass wall was observed, and test with $\mathrm{pH}$ indicator (Merck) showed $\mathrm{pH}=1$. The presence of chloride ions in the condensed water was confirmed through a test with $\mathrm{AgNO}_{3} / \mathrm{HNO}_{3}$ solution.

During the heating of the sucralose in a hot plate up to $140^{\circ} \mathrm{C}$, the darkening of the sample was observed showing that the thermal decomposition occurs without melting. This observation is in agreement with TG-DTA data and in disagreement with the melting point $\left(130^{\circ} \mathrm{C}\right)$ reported in the literature $[1,3,4]$.

This mistake was attributed to the fact that the authors of these references did not based their data on thermal analytical results. The TG-DTA curves clearly revels that the sharp endothermic peak is associated with mass loss, and can't be associated with melting of the material.

Therefore the use of sucralose in backed goods as in the case of cookies that are baked at a temperature of $210^{\circ} \mathrm{C}$ or graham crackers usually baked at a temperature of $230^{\circ} \mathrm{C}$ as described in reference [7], seem to be unsuitable since the thermal decomposition occurs at $119^{\circ} \mathrm{C}$ with liberation of constitution water and $\mathrm{HCl}$.

A close similarity is also observed in the DSC curves of the samples from Sigma and Viafarma, therefore only the DSC curve of the sucralose from Sigma is shown in Fig. 4, which was obtained up to $250^{\circ} \mathrm{C}$ due to the elimination of hydrogen chloride during the thermal decomposition as already confirmed by the tests previously described. This curve shows a sharp endothermic peak at $128^{\circ} \mathrm{C}$, corresponding to the first mass loss observed in the TG curve. The disagreement between the peaks temperatures observed in the DSC or DTA curves, undoubtedly is because the TG-DTA and DSC curves were obtained in enough different conditions.

Due to similarity between the reflectance infrared spectra of both sucralose samples, only the reflectance infrared spectra of sucralose from Sigma as received and heated up to $130^{\circ} \mathrm{C}$ are shown in Fig. 5.

The infrared spectra showed significant structural changes between the sample before and after heating, as can be seen in Fig. 5, where the appearance or disappearance of several peaks are observed. As an example the peak observed at $1711 \mathrm{~cm}^{-1}$ attributed to the carbonyl stretching frequency appeared after heated the sample is up to $130^{\circ} \mathrm{C}$.

These results are in agreement with the TG-DTA and DSC curves, indicating that the endothermic peak at $131^{\circ} \mathrm{C}$ (DTA) or $128^{\circ} \mathrm{C}$ (DSC) is not due to the melting, but is related to the thermal decomposition of the sucralose, with releasing of constitution water and hydrogen chloride. 


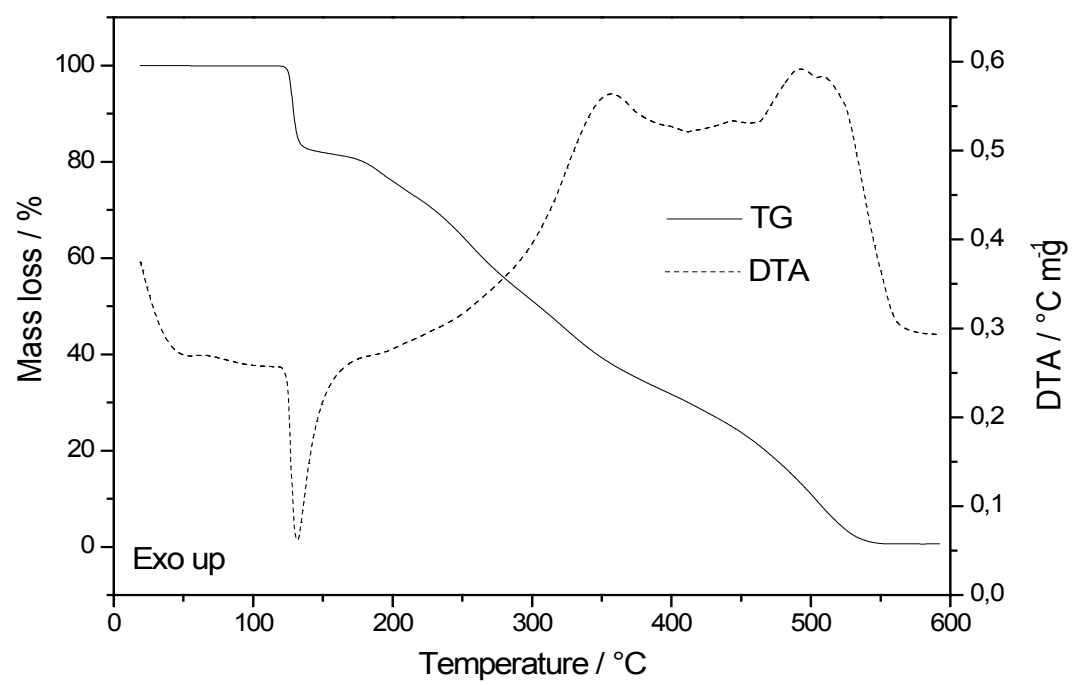

Fig. 2: TG and DTA curves of HPLC grade sucralose. $\left(\mathrm{m}_{\mathrm{i}}=7.195 \mathrm{mg}\right)$.

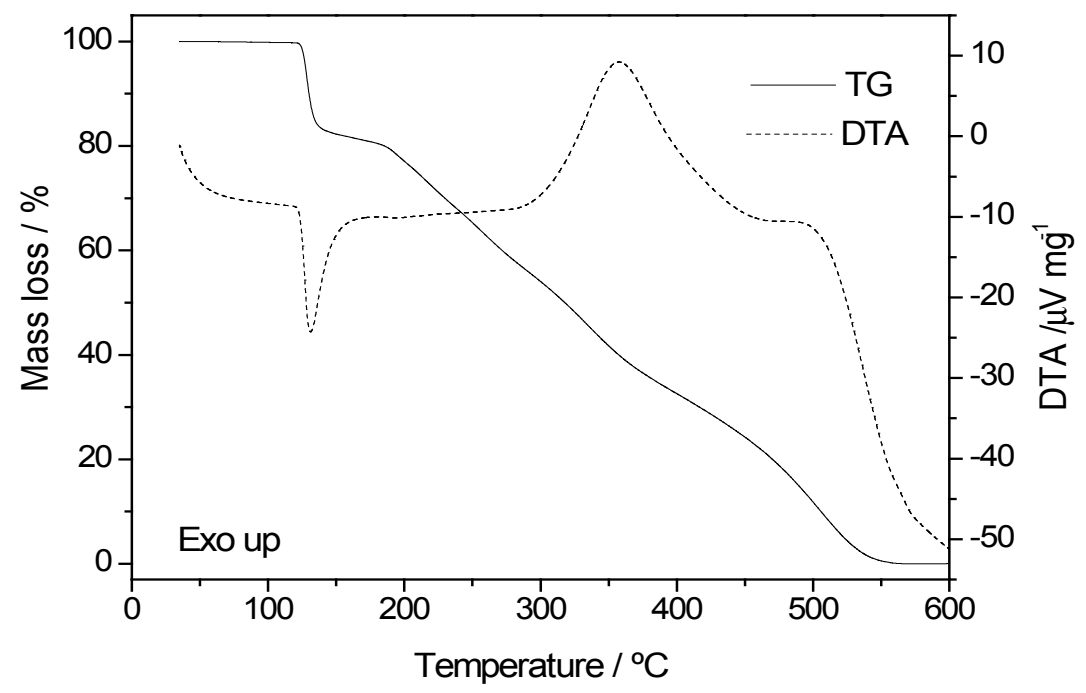

Fig. 3: TG and DTA curves of technical grade sucralose. $\left(\mathrm{m}_{\mathrm{i}}=5.174 \mathrm{mg}\right)$. 


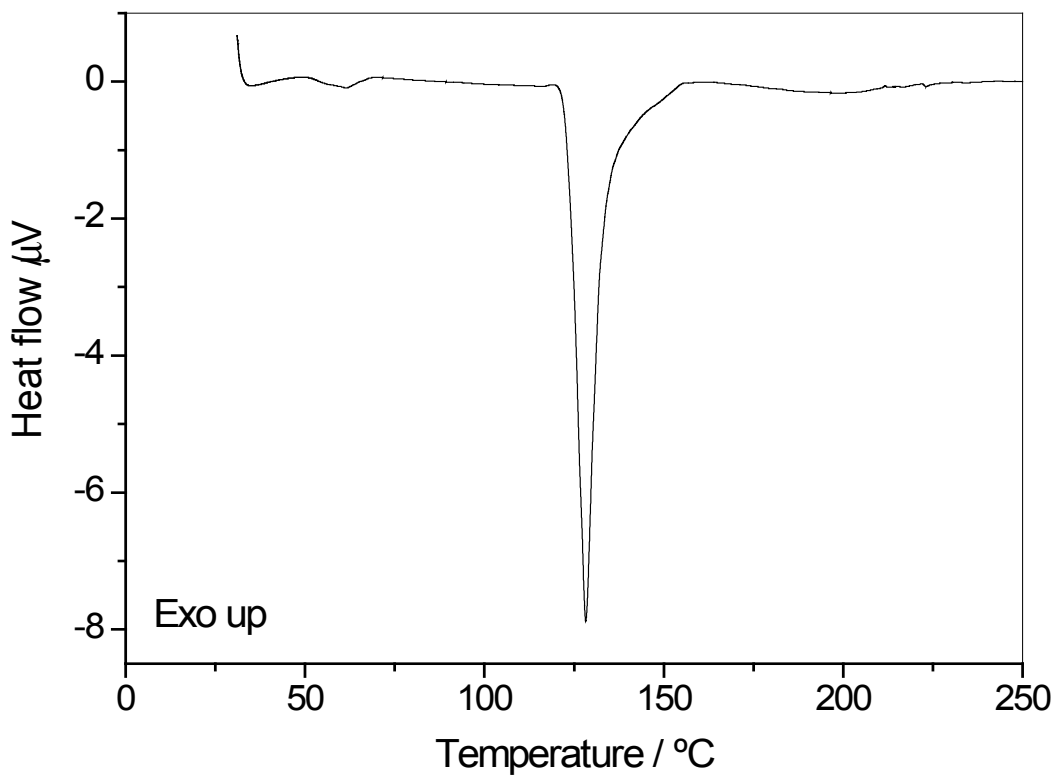

Fig. 4: DSC curve of HPLC grade sucralose $\left(\mathrm{m}_{\mathrm{i}}=3.004 \mathrm{mg}\right)$.

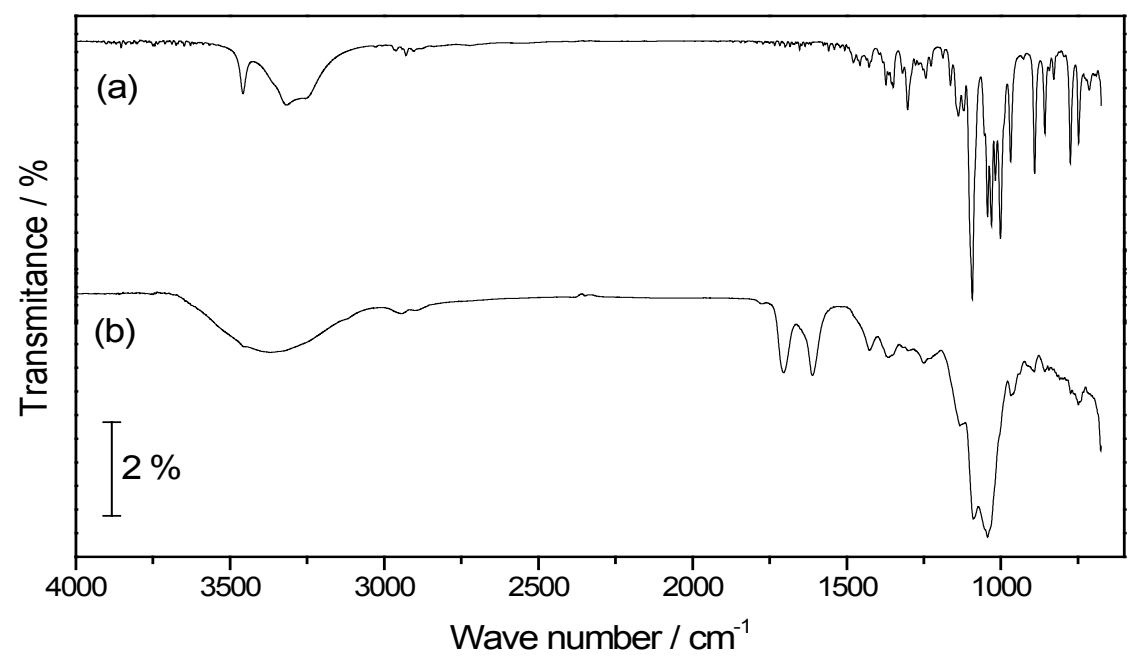

Fig. 5: Infrared spectra of: (a) Sucralose (HPLC grade) at room temperature; (b) Sucralose (HPLC grade) heated up to $130 \mathrm{oC}$. 


\section{Conclusion}

The TG-DTA and DSC data allowed us to verify that the sucralose is thermally stable up to $119^{\circ} \mathrm{C}$ and above this temperature the thermal decomposition takes place in three steps up to $550^{\circ} \mathrm{C}$ and without melting. The endothermic peak at $131^{\circ} \mathrm{C}$ (DTA) and $128^{\circ} \mathrm{C}$ (DSC) is due to the thermal decomposition with release of constitution water and hydrogen chloride.

The infrared spectra also confirm that the thermal decomposition occurs above $119^{\circ} \mathrm{C}$ in disagreement with the literature data.

\section{Acknowledgements}

The authors acknowledge FAPESP for the financial support and Prof. Dr. Marco Aurélio da Silva Carvalho Filho, for permitting the use of his DSC equipment from Shimadzu.

\section{References}

[1] G. E. Morlock, S. Prabha. J. Agric. Food Chem. 55 (2007) 7217-7223.

[2] M. Kroger, K. Meister, R. Kava. Compr. Rev. Food Sci. Food Saf. 5 (2006) 35-47.

[3] M. J. O'Neil, (Ed.) et al. The Merck Index. 13rd ed. Whithouse Station, 2001, pp. 8965.

[4] The United States Pharmacopeial Convention. Material Safety Data Sheet: Sucralose. Rockville. Catalog number: $1623626,2006$.

[5] N. M. Binns. Br. Nutr. Found. Nutr. Bull. 28 (2003) 5358.

[6] H. C. Grice, L. A. Goldsmith, Food Chem. Toxicol. 38 (2000) S1-S6.

[7] R. L. Barndt, G. Jackson, Food Technol. 44 (1990) 62-66. 